\title{
Study of Active Duty Military Personnel for Environmental Deployment Exposures: Pre- and Post-Deployment Spirometry
} (STAMPEDE II)

\author{
Michael J Morris, Andrew J Skabelund, Frederic A Rawlins III, Roger A Gallup, James K Aden, \\ and Aaron B Holley
}

\begin{abstract}
BACKGROUND: There is significant concern about the respiratory health of deployed military service members given the reported airborne hazards in southwest Asia, which range from geologic dusts, burn pit emissions, chemical exposures, and increased rates of smoking. There has been no previous comparison of pre- and post-deployment lung function in these individuals. METHODS: Military personnel who deployed to southwest Asia in support of ongoing military operations were recruited from the Soldier Readiness Processing Center at Fort Hood, Texas, from 2011 to 2014. The participants were asked to complete a brief survey on their respiratory health and perform both spirometry and impulse oscillometry studies at baseline with repeated survey and testing after deployment. RESULTS: Of the 1,693 deployed personnel who completed baseline examinations, 843 (50\%) completed post-deployment testing. Post-deployment values demonstrated no statistical or clinical change in spirometry, with an increase in mean $\pm \mathrm{SD} \mathrm{FEV}_{1}(\%$ predicted) from $95.2 \pm 12.6$ to $96.1 \pm 12.4(P=.14)$, increase in mean \pm SD FVC $(\%$ predicted $)$ from $95.9 \pm 11.8$ to $96.4 \pm 11.9(P=.32)$, and increase in mean $\pm \mathrm{SD} \mathrm{FEV}_{1} / \mathrm{FVC}$ from $81.5 \pm 5.9$ to $81.8 \pm 6.1(P=.29)$. Impulse oscillometry values showed statistical improvement with reduction in resistance (at $5 \mathrm{~Hz}$ and $20 \mathrm{~Hz}$ ) and reactance $($ at $5 \mathrm{~Hz}$ ). The presence of pre-deployment obstruction, self-reported asthma, smoking history, or increased body mass index also did not change spirometry values after deployment. DISCUSSION: To our knowledge, this was the first prospective evaluation of deploying military by using spirometry as an indicator for the possible development of pulmonary disease related to environmental exposures. Pre-deployment testing with spirometry and impulse oscillometry was unable to detect any significant change. In those with abnormal spirometry pre-deployment or asthma history, there was also not identifiable change that indicated worsening lung function. CONCLUSIONS: Utilization of spirometry for the deploying military population had little benefit and did not identify individuals with lung disease after deployment. Routine use was not warranted before or after deployment in the absence of pulmonary symptoms. Key words: military personnel; airborne particulate matter; exposure; impulse oscillometry; spirometry. [Respir Care 2019;64(5):536-544. () 2019 Daedalus Enterprises]
\end{abstract}

\section{Introduction}

There is ongoing discussion regarding the effect of deployment on the respiratory health of military personnel who

Dr Morris and Dr Holley are affiliated with the Pulmonary/Critical Care Service, Department of Medicine, Brooke Army Medical Center, Fort Sam Houston, San Antonio, Texas. Dr Skabelund is affiliated with the Pulmonary Disease Service, Wilford Hall Ambulatory Surgical Center, Lackland Air Force Base, San Antonio, Texas. Dr Rawlins III is affiliated deploy to southwest Asia in support of operations Iraqi Freedom, Enduring Freedom, and New Dawn. ${ }^{1}$ Deployed individuals may be exposed to significant levels of airborne particulate matter from geologic dusts, burn pit emissions, wasted

with the Pulmonary/Critical Care Service, Keesler Medical Center, Keesler Air Force Base, Biloxi Mississippi. Dr Gallup is affiliated with St. Francis Medical Center, Tulsa, Oklahoma. Dr Aden is affiliated with Graduate Medical Education, Brooke Army Medical Center, Fort Sam Houston, San Antonio, Texas. 
munitions, or limited exposures related to sulfur mine fires or chemical weapons caches. ${ }^{2}$ Current evidence for a causative association between these exposures and the development of chronic pulmonary disease is limited. ${ }^{3-5}$ Our initial study, STAMPEDE I, evaluated 50 soldiers within 6 months for new-onset respiratory symptoms during deployment. ${ }^{3}$ The 2010 Armed Forces Health Surveillance Center report ${ }^{6}$ concluded, based on very limited evidence, that exposures to burn pit smoke did not seem to increase the risk for pulmonary complications. In 2011, the Institute of Medicine expressed concern about burn pit particulate matter exposures but conceded that there was inadequate evidence to link these exposures to respiratory disease. ${ }^{7}$ The Navy Millennium Cohort Study and another study from the conflicts in southwest Asia demonstrated increases in deployment-related respiratory symptoms. ${ }^{8,9}$ Despite increases in symptoms, epidemiologic studies have not shown increases in respiratory disease. ${ }^{10}$

A Department of Defense/Veterans Affairs working group convened in 2010 to begin investigations into postdeployment lung disease. ${ }^{11}$ Recommendations from the initial meeting included pulmonary evaluation for individuals with chronic symptoms, abnormal pulmonary function testing, or reduced exercise tolerance. Assessment of the utility of pre- and post-deployment spirometry for all service members was also recommended to objectively assess deployment-related respiratory changes. However, Department of Defense representatives advocated conducting a clinical study before universal implementation of pre-deployment spirometry. ${ }^{12}$ The initial pre-deployment data were reported in 2017 by our study group and found that the deploying soldiers were older and heavier, and frequently smoked, and may have had undiagnosed predeployment lung disease. ${ }^{13}$ Abnormal spirometry was common $(22.3 \%)$ but did not correlate with underlying disease based on medical history and symptoms. The pre-deployment data also showed that self-reported asthma, symptoms of wheezing, and slower 2-mile $(3.2 \mathrm{~km})$ run times on physical fitness testing were predictive of abnormal spirometry. This study provided post-deployment follow-up to assess for changes in pulmonary function based

\footnotetext{
The opinions in this manuscript do not constitute endorsement by San Antonio Military Medical Center, the U.S. Army Medical Department, the U.S. Army Office of the Surgeon General, the Department of the Army, the Department of the Air Force, or the U.S. Government of the information contained therein.

Correspondence: Michael J Morris MD, Pulmonary Disease Service (MCHE-ZDM-P), Brooke Army Medical Center, 3551 Roger Brooke Drive, Fort Sam Houston, San Antonio TX 78234. E-mail: michael.j.morris34.civ@mail.mil.
}

DOI: $10.4187 /$ respcare.06396

\section{QUICK LOOK}

\section{Current knowledge}

To our knowledge, the role of pulmonary function testing in evaluating military personnel due to deploymentrelated exposures has not been previously studied. Although there are increases in respiratory symptoms, direct evidence for chronic respiratory disease caused by deployment is lacking. Identifying those individuals with evidence of disease is important to early recognition and treatment.

\section{What this paper contributes to our knowledge}

Screening with spirometry of all military personnel before and after deployment does not provide useful data on the presence or absence of underlying lung disease. Routine use is not warranted before or after deployment in the absence of known lung conditions or active pulmonary symptoms.

on pre-deployment risk factors and post-deployment symptoms.

\section{Methods}

A prospective study was conducted that involved Army personnel who underwent deployment to southwest Asia (Iraq, Afghanistan, Kuwait, or Qatar) from 2011 to 2014 in support of ongoing combat operations. All study participants were recruited from Fort Hood, Texas, during their centralized pre-deployment processing. Any soldier with a pending deployment to southwest Asia was eligible for study participation; there were no specified exclusion criteria. The Brooke Army Medical Center Institutional Review Board approved the study design and implementation; all the participants completed a written informed consent process.

Before deployment, all the participants completed a questionnaire and underwent baseline chest radiography, spirometry, and impulse oscillometry. An identical post-deployment evaluation was conducted in those individuals who returned through the Fort Hood Soldier Readiness Processing Center, usually within 1 to 2 wk of re-deployment from southwest Asia. The pre-deployment questionnaire collected basic demographic, smoking, and deployment data. The participants reported their current medications, medical history, pulmonary symptoms (dyspnea, cough, wheezing, sputum production, and exercise intolerance) and performance on the Army Physical Fitness Test to include 2-mile $(3.2 \mathrm{~km})$ run times. The postdeployment questionnaire detailed deployment airborne ex- 
Pre- And Post-Deployment Seirometry in Active Duty Military

posures (dust and/or sand, vehicle exhaust, burning trash, and industrial fumes), smoking history, respiratory illnesses, and respiratory symptoms before, during, and after deployment.

The participants performed spirometry, conducted by the same respiratory therapist who did the pre-deployment evaluation by using a VMax spirometer (Vyaire Medical, Yorba Linda, California). They underwent a standard forced expiratory maneuver from maximal inhalation to maximal exhalation to record $\mathrm{FEV}_{1}$, and $\mathrm{FVC}$ in accordance with the American Thoracic Society standards for spirometry quality and reproducibility. No post-bronchodilator assessments were obtained. Obstruction on spirometry was defined as $\mathrm{FEV}_{1} / \mathrm{FVC}$ below the lower limit of normal as defined by the National Health and Nutrition Examination Survey III reference values. ${ }^{14}$ Supranormal spirometry was defined as an $\mathrm{FEV}_{1}$ or $\mathrm{FVC}>110 \%$ predicted. ${ }^{15}$ Impulse oscillometry was also conducted as part of the evaluation before and after deployment. Oscillatory resistance was obtained by using system software (MasterScreen IOS Impulse Oscillometry, Vyaire Medical, San Diego, California). Testing was performed according to published guidelines and measurements of resistance at $5 \mathrm{~Hz}$ (total respiratory resistance), resistance at $20 \mathrm{~Hz}$ (proximal resistance), and reactance at $5 \mathrm{~Hz}$ (distal capacitive reactance) were recorded. ${ }^{16,17}$

Mean \pm SD was used as summary statistics for continuous variables, such as spirometry data, age, and body mass index (BMI). These variables were analyzed by using the Student $t$ test and analysis of variance or the Wilcoxon test when appropriate. Categorical variables, such as risk factors during deployment, sex, and race, were summarized by using percentages and were analyzed by using chi-square tests or the Fisher exact test when appropriate. Significance for results was established when $P$ values were $<.05$. Potential risk factors (smoking, presence of obstruction, increased BMI, or self-reported asthma) for spirometric obstruction during deployment and post-deployment symptoms (dyspnea, cough, wheezing, sputum production, and decreased exercise tolerance) were entered into a multivariable logistic regression model. Odds ratios, along with their corresponding 95\% CIs were reported, along with the area under the curve for the model. All statistical analyses were performed by using SPSS v 22.0 (IBM, Armonk, New York).

\section{Results}

The original cohort consisted of 1,693 personnel who completed the pre-deployment evaluation; data from 843 participants were collected after southwest Asia deployment, from 2012 to 2014. This represented 50\% of the original cohort reported previously. ${ }^{13}$ Baseline demographics for the returning cohort are shown in Table 1. These
Table 1. Demographics of Pre-Deployment Vs Post-Deployment Cohorts

\begin{tabular}{lcc}
\hline \hline \multicolumn{1}{c}{ Demographic } & $\begin{array}{c}\text { Pre-Deployment } \\
\text { Cohort }\end{array}$ & $\begin{array}{c}\text { Post-Deployment } \\
\text { Cohort }\end{array}$ \\
\hline $\begin{array}{l}\text { Age, mean } \pm \text { SD y } \\
\text { Sex, } n(\%)\end{array}$ & $32.2 \pm 9.1$ & $32.9 \pm 9.2$ \\
Male & $1,407(83.1)$ & $703(83.4)$ \\
Female & $286(16.9)$ & $140(16.6)$ \\
Race, $n(\%)$ & & \\
African-American & $343(20.2)$ & $165(19.6)$ \\
Asian & $76(4.5)$ & $36(4.3)$ \\
White & $979(57.8)$ & $492(58.4)$ \\
Hispanic & $295(17.4)$ & $150(17.8)$ \\
Body mass index, $n(\%)$ & & $201(23.8)$ \\
$<25.0 \mathrm{~kg} / \mathrm{m}^{2}$ & $452(26.7)$ & $465(55.2)$ \\
25.0-29.9 kg/m ${ }^{2}$ & $903(53.3)$ & $177(21.0)$ \\
$>30.0 \mathrm{~kg} / \mathrm{m}^{2}$ & $338(20.0)$ & \\
Smoking, $n(\%)$ & & $591(70.1)$ \\
Never & $1,106(65.3)$ & $95(11.3)$ \\
Former & $327(19.3)$ & $245(29.1)$ \\
Current & $253(14.9)$ & $296(35.1)$ \\
Duty status, $n(\%)$ & & $290(35.1)$ \\
Active duty & $706(41.7)$ & \\
National Guard & $429(25.3)$ & \\
Reservist & $516(30.5)$ & \\
\hline
\end{tabular}

personnel were predominantly deployed to Afghanistan for an average of $9.5 \pm 1.3$ months. There was no difference in baseline demographics in the returning cohort (age, sex, ethnicity, BMI, smoking history, or Army branch) from the original pre-deployment cohort. Nearly $30 \%$ of the participants were current or former smokers, and $74 \%$ of the soldiers were classified as overweight or obese based on BMI.

The returning cohort noted frequent exposure to airborne hazards. Frequency of exposures were quantified by using a scale of 0 , none; 1 , occasionally; 2 , regularly; and 3 , continuously. The mean symptom score for Dust and/or sand exposure was the most common, at $1.97 \pm 0.74$, vehicle exhaust at $1.68 \pm 0.76$, burn pit smoke at $1.58 \pm 0.83$, and other fumes at $1.49 \pm 0.86$. The mean symptom score related to these exposures $(0$, none; 1 , mild; 2 , moderate; 3 , severe) were quantified as less than mild for cough $(0.26 \pm 0.43)$, wheeze $(0.08 \pm 0.27)$, dyspnea $(0.15 \pm 0.35)$, decreased exercise tolerance $(0.10 \pm 0.30)$, and sputum production $(0.09 \pm 0.28)$. The overall frequency of respiratory symptoms during the deployment period is shown in Figure 1. Self-reported symptoms increased during deployment and returned closer to pre-deployment levels on return to the United States. Cough was the most frequently reported symptom but occurred on average fewer than two times weekly. There was no clinically or statistically significant increase in symptoms during deployment compared with reported pre-deployment levels. 


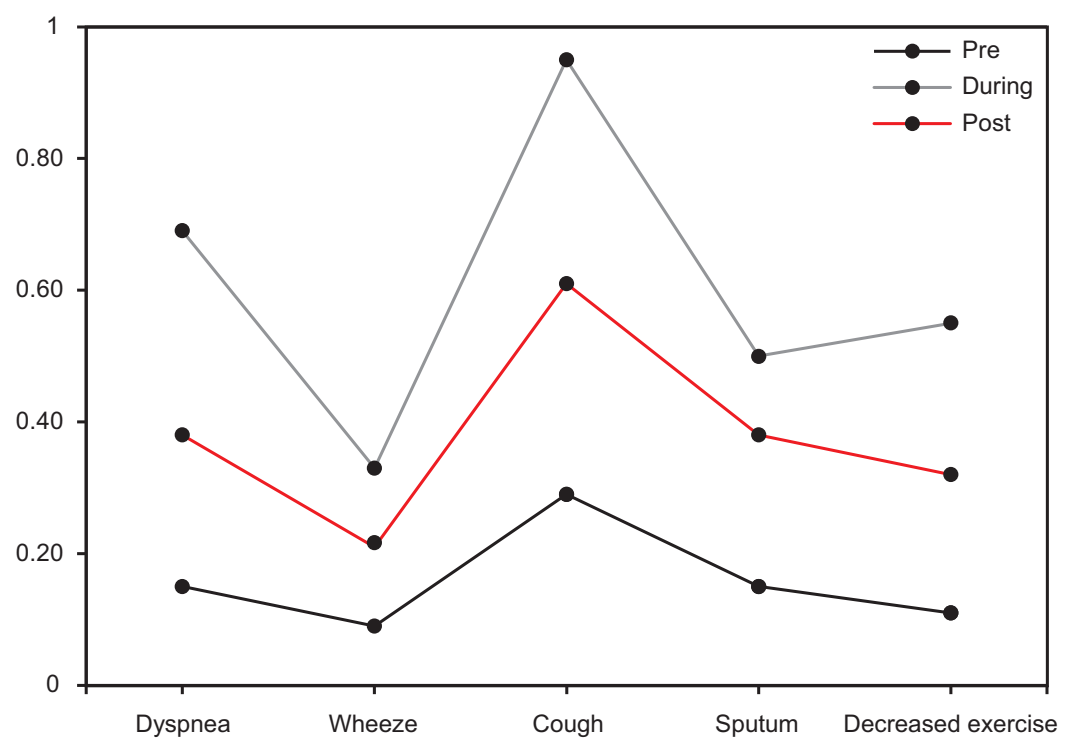

Fig. 1. Self-reported pulmonary symptoms. Self-reported respiratory symptoms before, during, and after deployment: 0 , never; $1,<2$ times weekly; 2, 2-5 times weekly; 3, daily.

Table 2. Pulmonary Function Testing: Pre- Vs Post-Deployment

\begin{tabular}{|c|c|c|c|c|}
\hline Test & Pre-Deployment Cohort* & Pre-Deployment Cohort $\dagger$ & Post-Deployment Cohort & $P \ddagger$ \\
\hline \multicolumn{5}{|l|}{ Spirometry } \\
\hline Subjects, $n$ & 1,693 & 843 & 843 & \\
\hline $\mathrm{FEV}_{1}$, mean $\pm \mathrm{SD} \%$ predicted & $94.8 \pm 12.7$ & $95.2 \pm 12.6$ & $96.1 \pm 12.4$ & .14 \\
\hline $\mathrm{FVC}$, mean $\pm \mathrm{SD} \%$ predicted & $95.5 \pm 11.9$ & $95.9 \pm 11.8$ & $96.4 \pm 11.9$ & .32 \\
\hline $\mathrm{FEV}_{1} / \mathrm{FVC}$, mean $\pm \mathrm{SD} \%$ & $81.7 \pm 6.4$ & $81.5 \pm 5.9$ & $81.8 \pm 6.1$ & .29 \\
\hline $\mathrm{FEF}_{25-75 \%}$, mean $\pm \mathrm{SD} \%$ predicted & $96.6 \pm 25.9$ & $96.5 \pm 25.5$ & $98.1 \pm 25.9$ & .19 \\
\hline \multicolumn{5}{|l|}{ Supranormal, $n(\%)$} \\
\hline Subjects & $245(14.5)$ & $129(15.3)$ & $158(18.7)$ & \\
\hline FVC,$>110 \%$ predicted & $190(11.2)$ & $101(12.0)$ & $114(13.5)$ & NA \\
\hline $\mathrm{FEV}_{1},>110 \%$ predicted & $180(10.6)$ & $97(10.7)$ & $116(13.8)$ & NA \\
\hline \multicolumn{5}{|l|}{ Impulse oscillometry } \\
\hline Subjects, $n$ & 1,654 & 843 & 843 & \\
\hline Resistance at $5 \mathrm{~Hz}$ & $4.39 \pm 1.48$ & $4.34 \pm 1.47$ & $4.12 \pm 1.37$ & .002 \\
\hline Resistance at $20 \mathrm{~Hz}$ & $3.53 \pm 1.06$ & $3.49 \pm 1.08$ & $3.33 \pm 0.92$ & $<.001$ \\
\hline Reactance at $5 \mathrm{~Hz}$ & $-1.49 \pm 0.71$ & $-1.48 \pm 0.74$ & $-1.37 \pm 0.73$ & $<.001$ \\
\hline \multicolumn{5}{|c|}{$\begin{array}{l}\text { * All the subjects enrolled in the initial cohort. } \\
\dagger \text { Subjects who completed the post-deployment evaluation. } \\
\ddagger P \text { values represent comparison of values between subjects }(n=843) \text { with pre- and post-deployment evaluation. } \\
\mathrm{FEF}_{25-75 \%}=\text { forced expiratory flow during the middle half of the } \mathrm{FVC} \text { maneuver } \\
\mathrm{NA}=\text { not applicable }\end{array}$} \\
\hline
\end{tabular}

Mean pre- and post-deployment spirometry data for the initial cohort and returning cohort are presented in Table 2. No statistical differences were noted between the overall and returning cohorts. For the returning cohort, there was a minimal nonsignificant increase in all post-deployment spirometry values $\left(\mathrm{FEV}_{1}, \mathrm{FVC}\right.$, and $\left.\mathrm{FEV}_{1} / \mathrm{FVC}\right)$ compared with pre-deployment values. These values were not clinically important in terms of spirometry interpretation. A similar finding was noted with impulse oscillometry val- ues, with significant decreases in resistance (resistance at $5 \mathrm{~Hz}$ and resistance at $20 \mathrm{~Hz}$, and improvement in reactance (reactance at $5 \mathrm{~Hz}$ ) values. There continued to be a percentage of soldiers (18.7\%) with supranormal values, which increased slightly above pre-deployment findings $(14.5 \%)$.

There were 116 individuals $(19 \%)$ in the cohort identified with obstruction $\left(\mathrm{FEV}_{1} / \mathrm{FVC}<\mathrm{LLN}\right)$ based on $\mathrm{Na}$ tional Health and Nutrition Examination Survey III refer- 
Pre- And Post-Deployment Seirometry in Active Duty Military

Table 3. Pulmonary Function Testing With Airway Obstruction $\left(\mathrm{FEV}_{1} / \mathrm{FVC}<\mathrm{LLN}\right)$

\begin{tabular}{|c|c|c|c|c|}
\hline Spirometry & $\begin{array}{c}\text { Pre-Deployment } \\
\text { Cohort }(\text { mean } \pm \text { SD) }\end{array}$ & $\begin{array}{c}\text { Post-Deployment } \\
\text { Cohort (mean } \pm \text { SD) }\end{array}$ & $\%$ Change (mean $\pm \mathrm{SD})$ & $P$ \\
\hline \multicolumn{5}{|l|}{ Obstruction (all) $(N=116)$} \\
\hline $\mathrm{FEV}_{1}, \%$ predicted & $85.4 \pm 11.9$ & $87.9 \pm 13.2$ & $4.0 \pm 9.7$ & .02 \\
\hline FVC, $\%$ predicted & $97.2 \pm 12.9$ & $99.0 \pm 12.5$ & $0.8 \pm 8.2$ & .01 \\
\hline $\mathrm{FEV}_{1} / \mathrm{FVC}, \%$ & $72.2 \pm 5.4$ & $73.2 \pm 5.9$ & $2.8 \pm 5.9$ & .90 \\
\hline $\mathrm{FEF}_{25-75 \%}, \%$ predicted & $63.8 \pm 15.7$ & $68.6 \pm 19.0$ & $9.0 \pm 15.9$ & .01 \\
\hline \multicolumn{5}{|c|}{ Obstruction (pre-deployment) $(n=33)$} \\
\hline $\mathrm{FEV}_{1}, \%$ predicted & $84.1 \pm 10.5$ & $92.9 \pm 10.5$ & $8.8 \pm 10.7$ & $<.001$ \\
\hline FVC, \% predicted & $97.2 \pm 11.5$ & $97.8 \pm 9.5$ & $0.6 \pm 7.8$ & .68 \\
\hline $\mathrm{FEV}_{1} / \mathrm{FVC}, \%$ & $71.5 \pm 4.3$ & $78.5 \pm 4.2$ & $6.9 \pm 6.6$ & $<.001$ \\
\hline $\mathrm{FEF}_{25-75 \%}, \%$ predicted & $62.2 \pm 9.4$ & $80.5 \pm 17.7$ & $18.3 \pm 18.0$ & $<.001$ \\
\hline \multicolumn{5}{|c|}{ Obstruction (pre-, post-deployment) $(n=54)$} \\
\hline $\mathrm{FEV}_{1}, \%$ predicted & $83.8 \pm 13.1$ & $84.8 \pm 14.1$ & $1.1 \pm 7.7$ & .31 \\
\hline FVC, $\%$ predicted & $98.8 \pm 13.1$ & $99.7 \pm 14.1$ & $0.9 \pm 8.6$ & .42 \\
\hline $\mathrm{FEV}_{1} / \mathrm{FVC}, \%$ & $69.8 \pm 4.1$ & $70.0 \pm 4.3$ & $0.2 \pm 3.6$ & .65 \\
\hline $\mathrm{FEF}_{25-75}, \%$ predicted & $58.0 \pm 14.2$ & $61.3 \pm 16.0$ & $3.3 \pm 11.1$ & .02 \\
\hline \multicolumn{5}{|c|}{ Obstruction (post-deployment) $(n=29)$} \\
\hline $\mathrm{FEV}_{1}, \%$ predicted & $90.1 \pm 10.3$ & $86.8 \pm 9.6$ & $-3.3 \pm 6.8$ & .02 \\
\hline FVC, $\%$ predicted & $94.2 \pm 13.8$ & $101.0 \pm 12.6$ & $6.8 \pm 12.7$ & .01 \\
\hline $\mathrm{FEV}_{1} / \mathrm{FVC}, \%$ & $77.6 \pm 4.6$ & $69.7 \pm 6.4$ & $-7.9 \pm 8.5$ & $<.001$ \\
\hline $\mathrm{FEF}_{25-75}, \%$ predicted & $76.6 \pm 16.9$ & $63.5 \pm 13.7$ & $-10.9 \pm 18.2$ & .01 \\
\hline
\end{tabular}

ence values (Table 3). ${ }^{14}$ Eighty seven had obstruction before deployment; obstruction remained in 54 (47\%) on postdeployment spirometry, and $33(28 \%)$ normalized. An additional 29 individuals (25\%) had normal pre-deployment spirometry and developed obstruction after deployment. Analysis of the overall cohort demonstrated no statistically significant change in spirometry values for those identified with obstruction. In those individuals with pre- and postdeployment obstruction, there was a small improvement in $\mathrm{FEV}_{1}, \mathrm{FVC}$, and $\mathrm{FEV}_{1} / \mathrm{FVC}$. Of the 29 subjects who developed obstructive indices, $13(45 \%)$ had an $\mathrm{FEV}_{1}$ of $>90 \%$ predicted. Similar findings were noted in the predeployment obstructed (33\%) and pre- and post-deployment obstructed (32\%) groups.

Because cigarette smoking, self-reported asthma, and increased BMI may impact spirometry, subgroup analyses by these factors was performed (Table 4). All 3 groups demonstrated slight improvement in post-deployment spirometry compared with pre-deployment values. Age, asthma, obesity, smoking status, and sex were entered into a logistic regression model to predict obstruction after deployment. The results showed that only age and asthma were significantly predictive $(P=.02$ and .045 , respectively). The odds ratios and their corresponding 95\% CIs for the model are presented in Table 5. Even though there were statistically significant factors in the model, the area under the curve for the model was only 0.624 , which indicated that it was poorly predictive. Further subgroup analysis of post-deployment symptoms identified only selfreported moderate wheezing correlated with post-deployment obstruction $(P=.03)$ (Table 6).

\section{Discussion}

The respiratory effects from large-scale deployment of military forces to austere environments remain a concern to the United States military. In southwest Asia, since 2003, there have been nearly 3.5 million military personnel deployed in support of military operations. This theater of operations poses various airborne hazards, predominantly composed of geologic dusts with particulate matter of $<5 \mu$ in size. ${ }^{2}$ Other potential hazards include smoke from large burn pits, chemical munitions, urban air pollution, and sulfur mine fires. Neither the short- nor longterm effects on pulmonary health have been fully elucidated, but the potential detriment to lung function from airborne particulate matter remains. ${ }^{1}$ This study evaluated whether pre-deployment spirometry and impulse oscillometry would identify service members at risk for lung function decline. Our results indicated that screening spirometry and impulse oscillometry before deployment did not predict post-deployment lung function abnormalities, and both modalities showed an overall slight improvement. However, moderate wheezing ( $>2$ times weekly) was the single symptom that correlated with post-deployment obstruction. 
Table 4. Pulmonary Function Testing Based on Risk Factors

\begin{tabular}{|c|c|c|c|c|}
\hline Spirometry & Pre-Deployment Cohort & Post-Deployment Cohort & $\%$ Change & $P$ \\
\hline \multicolumn{5}{|l|}{ Smoking } \\
\hline Subjects, $n$ & 252 & 252 & & \\
\hline $\mathrm{FEV}_{1}$, mean $\pm \mathrm{SD} \%$ predicted & $94.7 \pm 11.7$ & $96.7 \pm 11.9$ & 2.0 & .053 \\
\hline $\mathrm{FVC}$, mean $\pm \mathrm{SD} \%$ predicted & $95.6 \pm 11.2$ & $97.3 \pm 11.8$ & 1.7 & .08 \\
\hline $\mathrm{FEV}_{1} / \mathrm{FVC}$, mean $\pm \mathrm{SD} \%$ & $81.3 \pm 5.6$ & $81.6 \pm 6.0$ & 0.3 & .58 \\
\hline $\mathrm{FEF}_{25-75 \%}$, mean $\pm \mathrm{SD} \%$ predicted & $95.7 \pm 25.2$ & $98.9 \pm 25.3$ & 3.3 & .15 \\
\hline \multicolumn{5}{|l|}{ Asthma } \\
\hline Subjects, $n$ & 39 & 39 & & \\
\hline $\mathrm{FEV}_{1}$, mean $\pm \mathrm{SD} \%$ predicted & $92.3 \pm 16.3$ & $93.8 \pm 17.2$ & 1.4 & .71 \\
\hline $\mathrm{FVC}$, mean $\pm \mathrm{SD} \%$ predicted & $96.5 \pm 13.1$ & $97.2 \pm 14.6$ & 0.7 & .83 \\
\hline $\mathrm{FEV}_{1} / \mathrm{FVC}$, mean $\pm \mathrm{SD} \%$ & $78.5 \pm 8.3$ & $79.2 \pm 7.9$ & 0.6 & .73 \\
\hline $\mathrm{FEF}_{25-75 \%}$, mean $\pm \mathrm{SD} \%$ predicted & $85.4 \pm 31.0$ & $87.9 \pm 29.1$ & 2.5 & .71 \\
\hline \multicolumn{5}{|l|}{ Body mass index of $25-30 \mathrm{~kg} / \mathrm{m}^{2}$} \\
\hline Subjects, $n$ & 474 & 474 & & \\
\hline $\mathrm{FEV}_{1}$, mean $\pm \mathrm{SD} \%$ predicted & $95.1 \pm 12.3$ & $96.1 \pm 12.2$ & 0.7 & .36 \\
\hline $\mathrm{FVC}$, mean $\pm \mathrm{SD} \%$ predicted & $95.8 \pm 11.8$ & $96.5 \pm 11.7$ & 1.0 & .19 \\
\hline $\mathrm{FEV}_{1} / \mathrm{FVC}$, mean $\pm \mathrm{SD} \%$ & $81.2 \pm 5.7$ & $81.5 \pm 5.8$ & 0.3 & .43 \\
\hline $\mathrm{FEF}_{25-75 \%}$, mean $\pm \mathrm{SD} \%$ predicted & $96.1 \pm 25.4$ & $97.7 \pm 25.9$ & 1.7 & .34 \\
\hline \multicolumn{5}{|l|}{ Body mass index $>30 \mathrm{~kg} / \mathrm{m}^{2}$} \\
\hline Subjects, $n$ & 168 & 168 & & \\
\hline $\mathrm{FEV}_{1}$, mean $\pm \mathrm{SD} \%$ predicted & $94.0 \pm 12.6$ & $97.0 \pm 13.3$ & 3.1 & .02 \\
\hline $\mathrm{FVC}$, mean $\pm \mathrm{SD} \%$ predicted & $93.9 \pm 11.2$ & $96.8 \pm 12.3$ & 3.0 & .031 \\
\hline $\mathrm{FEV}_{1} / \mathrm{FVC}$, mean $\pm \mathrm{SD} \%$ & $81.4 \pm 2.3$ & $81.7 \pm 6.3$ & 0.2 & .82 \\
\hline $\mathrm{FEF}_{25-75 \%}$, mean $\pm \mathrm{SD} \%$ predicted & $98.6 \pm 27.1$ & $102.7 \pm 27.7$ & 4.2 & .16 \\
\hline
\end{tabular}

Table 5. Logistic Regression Analysis for Obstruction

\begin{tabular}{lcl}
\hline \hline \multicolumn{1}{c}{ Term } & Odds Ratio $(95 \% \mathrm{CI})$ & $P$ \\
\hline Increased Age, y & $1.03(1.00-1.07)$ & .02 \\
Asthma & $2.50(1.02-6.11)$ & .045 \\
Obesity & $1.30(0.67-2.54)$ & .44 \\
Smoking & $1.29(0.73-2.27)$ & .38 \\
Male & $1.75(0.84-3.67)$ & .14 \\
& & \\
\hline$P<.05$ significant. & & \\
\hline
\end{tabular}

Our prospective evaluation of military personnel before and after deployment led to several important findings. Respiratory symptoms in the deployed population were commonplace, likely due to dust or air pollution exposures, but they generally decreased after deployment. The slight improvement in spirometry and impulse oscillometry values was not clinically important and highlighted the variability of spirometry. In addition, those individuals with baseline obstruction $(10.3 \%)$ had a minimal change in their spirometry, and nearly one third normalized after deployment. Subgroup analyses of smoking (29.9\%), increased BMI of $>30 \mathrm{~kg} / \mathrm{m}^{2}(19.9 \%)$, or a self-reported history of asthma (4.6\%) did not demonstrate significant
Table 6. Subgroup Analysis of Spirometry Based on PostDeployment Symptoms

\begin{tabular}{llcc}
\hline \hline \multicolumn{1}{c}{ Symptom } & \multicolumn{1}{c}{ Level } & Results, mean $\pm \mathrm{SD}$ & $\begin{array}{c}P \text {, Wilcoxon } \\
\text { Test }\end{array}$ \\
\hline Dyspnea & Normal & $1.37 \pm 0.66$ & .37 \\
& Obstruction & $1.49 \pm 0.80$ & \\
Wheezing & Normal & $1.21 \pm 0.55$ & .03 \\
& Obstruction & $1.41 \pm 0.79$ & \\
Cough & Normal & $1.65 \pm 0.89$ & .74 \\
Sputum & Obstruction & $1.59 \pm 0.83$ & \\
& Normal & $1.38 \pm 0.80$ & .73 \\
Exercise tolerance & Obstruction & $1.42 \pm 0.86$ & \\
& Norm & $1.33 \pm 0.67$ & .25 \\
& Obstruction & $1.38 \pm 0.65$ & \\
\hline
\end{tabular}

change in pre- and post-deployment spirometry. Most importantly, the $50 \%$ rate of individuals who repeated spirometry after deployment highlighted the difficulty of studying any population given the constraints of time, resources, and the geographic distribution of military personnel.

We first reported the data from this cohort of 1,693 participants based on the pre-deployment spirometry findings. ${ }^{13}$ Notably, more than one third of surveyed solders 
had a smoking history; $73 \%$ were overweight or obese, with a BMI $>25 \mathrm{~kg} / \mathrm{m}^{2}$; and $6.2 \%$ reported a history of asthma. Abnormal spirometry was found in $22.3 \%$ of the participants, with nearly one third who demonstrated supranormal obstruction. Those soldiers with abnormal spirometry compared to normal spirometry reported more asthma (10.1 vs $5.1 \%$ ), failed physical fitness tests (9.0 vs $4.6 \%$ ), and increased frequency of respiratory symptoms (32.8 vs $24.3 \%$ ). Based on the pre-deployment findings, we expected to identify some change in the cohort after deployment. However, the participants with baseline obstruction, history of smoking, increased BMI, or self-reported asthma had no significant change in spirometry to warrant additional evaluation. Even the participants with baseline obstruction who remained obstructed $(n=54)$ only had a minimal $0.2 \%$ change in $\mathrm{FEV}_{1} / \mathrm{FVC}$. This indicated that, despite the potential airborne particulate matter, these participants may not have had underlying inflammation and simply represented a normal variant because nearly one third had supranormal obstruction.

We recently confirmed the high number of individuals with abnormal spirometry in another military population. A study of 900 non-deployed military personnel identified nearly $11 \%$ had non-specific changes with a single spirometry. ${ }^{18}$ Ninety-eight subjects were identified with abnormal spirometry, including 33 obstructive, 44 restrictive, 3 mixed, and 18 isolated flow-volume loop abnormalities. Historical features (smoking, exertional dyspnea, cough, asthma, or 2-mile $(3.2 \mathrm{~km})$ physical fitness test run failure) had no effect on the probability of an abnormal spirometry result $(P=.56)$. Although physical fitness test failure probability is strongly affected by exertional dyspnea and current smoking, abnormal spirometry results did not have a statistically significant effect $(P=.38) .{ }^{18}$ Spirometry as a screening tool was poorly predictive for respiratory symptoms or decreased exercise tolerance in this non-deployed military cohort. Further evidence was provided by the current study for a deployed population.

An initial workshop at the 2011 Department of Defense/Veterans Affairs Airborne Hazards Conference ${ }^{19}$ addressed the potential adoption of screening spirometry in military personnel. Four issues were raised as potential barriers to implementation: cost, reliability, the conduct of pre- and post-deployment spirometry, and use of spirometry in the military population to detect new pulmonary disease. ${ }^{19}$ The United States Army Public Health Command provided an in-depth analysis for a single spirometry examination and projected start-up costs alone to be nearly $\$ 35$ million. Primary issues in periodic spirometry evaluation are to establish good baseline measurement, maintain quality and within-person reproducibility, and identify individuals with excessive lung function decline. ${ }^{20}$ Ensuring consistent quality data would be a challenge given the widespread distribution of military personnel. Based on current epidemiologic data, the proportion of military personnel who develop pulmonary disease related to deployment is limited; as suggested, there would be no benefit in obtaining baseline spirometry for the vast majority of military personnel who never develop pulmonary disease. ${ }^{10}$

Both asthma and airway hyperreactivity are common in military personnel with respiratory symptoms. ${ }^{21}$ These conditions no longer automatically disqualify individuals from military service, and personnel may remain on active duty with well-controlled disease. It has been postulated that extreme southwest Asia climate conditions, geologic dust, and burn pit smoke exposures may worsen asthma control and increase exacerbations. Roop et $\mathrm{al}^{22}$ surveyed deploying Army personnel and identified 5\% of troops with a pre-deployment diagnosis of asthma. Both those with asthma and those without asthma had increased respiratory symptoms during deployment, whereas those with asthma reported poor symptom control while in theater.

A single-center review of 6,000 Veterans Affairs medical records (International Classification of Diseases, 9th Revision diagnostic codes, with minimum pulmonary function testing data) noted higher rates of "new onset" asthma in deployed personnel from 2004 to 2007 compared with never-deployed personnel (6.6 vs $4.3 \%){ }^{4}$ This study did not address any asthma symptoms or related conditions that existed before deployment when assuming that the findings were all "new-onset asthma." Delvecchio et al ${ }^{5}$ conducted an in-depth medical record review of 400 active duty military personnel diagnosed with asthma who were undergoing a medical fitness for duty evaluation due to persistent asthma symptoms. Fifty percent had never deployed, 25\% were diagnosed before deployment, whereas $25 \%$ of the those with asthma were diagnosed after deployment. ${ }^{5}$ There were no differences in pulmonary function tests or asthma severity based on the time of diagnosis or deployment history. ${ }^{5}$

The utility of spirometry would be in a population with a higher rate of respiratory disease such as recommended for specific occupational exposures. However, both the epidemiologic and clinical data from southwest Asia deployments since 2013 have not demonstrated increases in lung disease. The United States Army Public Health Command evaluated trends in rates of chronic lung diseases in the military population from 2001 through $2013 . .^{10}$ Over the 13-y study period, rates of asthma and chronic bronchitis steadily decreased, whereas an increase in nonspecific bronchitis drove an overall increase in chronic respiratory disease. ${ }^{10}$ More focused evaluations of other disease processes, such as COPD and sarcoidosis, have also failed to demonstrated increases in diagnostic rates related to deployment. ${ }^{23,24}$ Two prospective studies of returning military personnel primarily identified asthma and non-spe- 
cific airway hyperreactivity as the primary respiratory disorder in their study populations. ${ }^{3,25}$ Longer deployments were associated with increased bronchodilator responsiveness, with a trend toward increased air-flow limitation. ${ }^{25}$

As part of the 2011 Department of Defense/Veterans Affairs Airborne Hazards workshop on spirometry, the following recommendation was made by Department of Defense representatives and have been confirmed by this study: "Department of Defense policy at present should not require routine surveillance spirometry in all military personnel. The burden of evaluating asymptomatic personnel with pulmonary function testing abnormalities would outweigh any benefit from early disease detection. No such recommendations exist for asthma and COPD screening for the general population and the incidence of other chronic lung diseases is extremely small." 12

\section{Conclusions}

Implementation of pre- and post-deployment spirometry would have significant logistic implications given the numbers ( $>3.5$ million personnel deployed), numerous military bases throughout the world, and quality data that could be obtained. Furthermore, there is no current system in the military electronic medical record to do serial tracking as is done in occupational surveillance. This study compared pre- and post-deployment pulmonary function testing in the general military population and showed a slight overall improvement in both spirometry and impulse oscillometry values, despite reported increases in respiratory symptoms. Further analysis of individuals with baseline obstruction or with risk factors, such as asthma, smoking, or increased BMI, also noted no significant changes. The use of routine spirometry to screen the re-deploying population for deployment-related lung disease was not shown to be beneficial. Spirometry in the military population would be most helpful in deployed individuals with persistent respiratory symptoms (specifically wheezing) as currently recommended by guidelines for the general population.

\section{ACKNOWLEDGMENTS}

The authors thank Lorraine Burroughs, for her performance of all pulmonary function studies during the conduct of this study.

\section{REFERENCES}

1. Morris MJ, Rawlins FA, Forbes DA, Skabelund AJ, Lucero PF. Deployment-related respiratory issues. US Army Med Dep J 2016: Apr-Sep;(2-16):173-178.

2. Weese CB, Abraham JH. Potential health implications associated with particulate matter exposure in deployed settings in southwest Asia. Inhal Toxicol 2009;21(4):291-296.

3. Morris MJ, Dodson DW, Lucero PF, Haislip GD, Gallup RA, Nicholson KL, Zacher LL. Study of active duty military for pulmonary disease related to environmental deployment exposures (STAMPEDE). Am J Respir Crit Care Med 2014;190(1):77-84.

4. Szema AM, Peters MC, Weissinger KM, Gagliano CA, Chen JJ. New-onset asthma among soldiers serving in Iraq and Afghanistan. Allergy Asthma Proc 2010;31(5):67-71.

5. DelVecchio SP, Collen JF, Zacher LL, Morris MJ. The impact of combat deployment on asthma diagnosis and severity. J Asthma 2015;52(4):363-369.

6. Armed Forces Health Surveillance Center. Epidemiological studies of health outcomes among troops deployed to burn pit sites. Silver Spring, MD; 2010.

7. Institute of Medicine. Long-term health consequences of exposure to burn pits in Iraq and Afghanistan. Washington, DC: The National Academies Press; 2011.

8. Sanders JW, Putnam SD, Frankart C, Frenck RW, Monteville MR, Riddle MS, et al. Impact of illness and non-combat injury during Operations Iraqi Freedom and Enduring Freedom (Afghanistan). Am J Trop Med Hyg 2005;73(4):713-719.

9. Smith B, Wong CA, Smith TC, Boyko EJ, Gacksetter GD, Margaret A. K. Ryan for the Millennium Cohort Study Team. Newly reported respiratory symptoms and conditions among military personnel deployed to Iraq and Afghanistan: A prospective population-based study. Am J Epidemiol 2009;170(11):1433-1442.

10. Abraham JH, Clark LL, Sharkey JM, Baird CP. Trends in rates of chronic obstructive respiratory conditions among US military personnel, 2001-2013. US Army Med Dep J 2014:Jul-Sep;33-43.

11. Rose C, Abraham J, Harkins D, Miller M, Morris M, Zacher L, et al. Overview and recommendations for medical screening and diagnostic evaluation for post-deployment lung disease in returning US warfighters. J Occup Environ Med 2012;54(6):746-751.

12. Zacher LL, Browning R, Bisnett T, Bennion JR, Postlewaite RC, Baird CP. Clarifications from representatives of the Department of Defense regarding the article "Recommendations for medical screening and diagnostic evaluation for post-deployment lung disease in returning US warfighters." J Occup Environ Med 2012;54(6):760761.

13. Skabelund AJ, Rawlins FA III, McCann ET, Lospinoso JA, Burroughs L, Gallup RA, Morris MJ. Pulmonary function and respiratory health of military personnel before Southwest Asia deployment. Respir Care 2017;62(9):1148-1155.

14. Hankinson JL, Odencrantz JR, Fedan KB. Spirometric reference values from a sample of the general U.S. population. Am J Respir Crit Care Med 1999;159(1):179-187.

15. Cochet AA, Lucero PF, Zacher LL, Morris MJ. Prevalence of supranormal pulmonary function testing values between a military and non-military cohort. Respir Care 2014;59(5):749-755.

16. Oostveen E, MacLeod D, Lorino H, Farré R, Hantos Z, Desager K, Marchal F; ERS Task Force on Respiratory Impedance Measurements. The forced oscillation technique in clinical practice: methodology, recommendations and future developments. Eur Respir J 2003; 22(6):1026-1041.

17. Bickel S, Popler J, Lesnick B, Eid N. Impulse oscillometry: interpretation and practical applications. Chest 2014;146(3):841-847.

18. Anderson DMF, Morris MJ, Ondrasik NR, Rawlins III, FA, Lospinoso JA, Zanders TB. Screening spirometry in military personnel correlates poorly with exercise tolerance and asthma history. Mil Med 2018 Mar 26. doi: 10.1093/milmed/usx195. [Epub ahead of print]

19. Morris MJ, Eschenbacher W. Discussion summary: recommendation for surveillance spirometry in military personnel. In: Baird CP, Harkins DK, editors. Airborne hazards related to deployment. Fort Sam Houston, Texas: Office of the Surgeon General, Borden Institute; 2015:95-102. 
20. Townsend MC, Lockey JE, Velez H, Carson AI, Cowl CT, Delclos GL, et al. ACOEM position statement. Spirometry in the occupational setting. American College of Occupational and Environmental Medicine. J Occup Environ Med 2000;42(3):228-245.

21. Morris MJ, Grbach VX, Deal LE, Boyd SY, Johnson JE, Morgan JA. Evaluation of exertional dyspnea in the active duty patient: The diagnostic approach and the utility of clinical testing. Mil Med 2002; 167(4):281-288.

22. Roop SA, Niven AS, Calvin BE, Bader J, Zacher LL. The prevalence and impact of respiratory symptoms in asthmatics and non-asthmatics during deployment. Mil Med 2007;172(12):1264-1269.
23. Matthews T, Abraham J, Zacher LL, Morris MJ. The impact of deployment on COPD in active duty military personnel. Mil Med 2014;179(11):1273-1278.

24. Hamilton J, McCann E, Rawlins F, Morris M. The effect of deployment on the severity of sarcoidosis in active duty military. Chest 2014;146 (4 Meeting Abstracts):366A.

25. Falvo MJ, Abraham JH, Osinubi OY, Klein JC, Sotolongo AM, Ndirangu D, et al. Bronchodilator responsiveness and airflow limitation are associated with deployment length and Iraq and Afghanistan veterans. J Occup Environ Med 2016;58(4):325328. 